\title{
The Relationship of Social Adjustment and Resilience with Attitudes Towards Drugs in High School Boy and Girl Students
}

\author{
Safiollah Hezarian ${ }^{1,2}$, Saeed Bakhtiarpour (iD ${ }^{2,}{ }^{*}$, Reza Pasha (iD) ${ }^{2}$, Parviz Asgari (iD ${ }^{2}$ and Fariba Hafezi (iD) ${ }^{2}$ \\ ${ }^{1}$ Department of Psychology, Khuzestan Science and Research Branch, Islamic Azad University, Ahvaz, Iran \\ ${ }^{2}$ Department of Psychology, Ahvaz Branch, Islamic Azad University, Ahvaz, Iran \\ "Corresponding author: Department of Psychology, Ahvaz Branch, Islamic Azad University, Ahvaz, Iran. Email: bakhtiyarpours@gmail.com
}

Received 2020 June 10; Revised 2020 October 04; Accepted 2020 October 10.

\begin{abstract}
Background: Drug abuse and its destructive consequences are among challenging issues concerning students' health.

Objectives: The present study aimed to investigate the relationship of social adjustment and resilience with attitude towards drugs in boy and girl students of Lali City.

Methods: The study was a descriptive correlational study performed by path analysis. The study population included 1500 boy and girl high school students of Lali City in the academic year of 2017 - 2018, among whom 133 boys and 142 girls were selected through multistage stratified sampling and using Cochran's formula. Research instruments included Bell's Adjustment Inventory (BAI) for Students, the Connor-Davidson Resilience scale (CD-RISC), and the Drug Attitude scale (DAS). The collected data were analyzed using SPSS version 23.

Results: The results revealed a significant negative relationship between social adjustment and girl students' attitudes towards drugs $(\mathrm{P}<0.001)$; however, there was no significant relationship between social adjustment and attitudes towards drugs in boy students. Meanwhile, there was no direct and significant relationship between resilience and attitudes towards drugs in boy and girl students. On the other hand, a significant positive relationship was observed between resilience and social adjustment in boys $(\mathrm{P}<$ $0.01)$ and girls $(\mathrm{P}<0.05)$. The indirect impact of resilience on the students' attitudes towards drugs, mediated by social adjustment, was not significant.

Conclusions: Resilience reduces stress, and as a result, students with more resilience seem to have better coping skills, higher social adjustment, and negative attitudes towards drugs.
\end{abstract}

Keywords: Drug Attitude, Resilience, Social Adjustment, Students

\section{Background}

Adolescence is an important period of life in terms of physical, social, mental, and cognitive growth (1). This period is a critical phase during which coping behaviors and response to environmental needs develop and flourish (2). Due to rapid physical, psychological, social, cultural, and cognitive changes, this period is accompanied by various health-threatening problems (3). Most health-threatening factors and adolescents' risky behaviors start and continue progressively in this period of life (4).

Drug abuse and its unfavorable consequences are among the most important concerns and social harms of the present era. As a social crisis and a destructive phenomenon, addiction leads to many risks and deaths worldwide (5). Risky behaviors and their negative consequences affect adolescents' health and can cause major threats to life (6). Drug abuse by adolescents imposes major costs, as well as social, psychological, economic, and health burdens on society $(7,8)$. Several studies have reported that at least in the first experience, the decision for drug abuse is affected by individuals' attitudes towards drugs. Evidence suggests that individuals' attitudes and mental norms affect their behaviors, and behavioral intentions are real determinants of the behavior. Studies suggest that adolescents' and young people's mental norms and attitudes form their intention about using drugs and then the act of drug abuse $(9,10)$.

Social adjustment is a psychological process based on which the person copes with or controls daily life demands and conflicts $(11,12)$. Social adjustment means to get along with social norms, observe social rules and principles, establish efficient social contacts, and try to be satisfied with them. A socially adjusted person can properly process the information received from the environment. Such a person can set a value system for himself/herself to avoid be- 
ing harmed by unfavorable mental fluctuations and disagreements with others (13). Afshari Azad et al. (14) showed that low self-esteem, emotional deficiencies, and inability to adapt to problems led to a positive attitude towards drugs. Murray et al. (15) showed that social adjustment had a mediating role in perpetrating risky health behaviors such as substance use. Curran (16) reported that cognitive flexibility positively predicted the social skills and social support of mothers and mature children. Chen et al. (17) reported that a poor social adjustment and low levels of family support unfavorably affected Internet addiction. Ray and Elliott (18) reported that the components of selfconcept and social skills were the indicators of social adjustment, and individuals with a higher level of social skills and more positive self-concept expressed higher levels of social adjustment and academic competency.

Resilience is one of fundamental personality constructs and is involved in determining the individual's capability of withdrawing and resuming efforts to confront and cope with problems. Resilience is a complex process adopted by different individuals, groups, and communities in different social and cultural groups (18-20). Ahmadi et al. (21) reported that academic resilience and procrastination predicted a tendency for substance abuse in secondary school students. Therefore, these risk factors need to be considered when planning preventive measures and interventions for this age group. Kennedy et al. (22) also showed that low-stress resilience during adolescence was associated with an increased risk of disadvantageous and addictive health behaviors. Moreover, Rutter (23) defined resilience as resistance to risky psychological experiences. In fact, resilience is characterized by the level of risk-taking, sensitivity to risk-taking, and tendency to reduce negative effects and interactions, foster positive interactions, and seek new opportunities. Arrington and Wilson (24) defined resilience as a protective process that decreases the probability of negative consequences. Studies on neighborhood and social resilience indicate the wide extent of this type of resilience that usually emphasizes the processes leading to the growth of social relationships, social structures, and collective performance, despite violent situations (24-26). Ghanbari-Talab and Fooladchang (27) reported that these two variables had a negative relationship with tendency to addiction, and also, it was found that mental viability and resilience could predict addiction susceptibility. Ganji and Tavakoli (28) reported that there was a significant negative relationship between psychological capital (self-efficacy, resilience, optimism, and hopefulness), academic resilience, and Internet addiction.

Sheydae and Pirkhaefi (29) reported that there was a positive and significant relationship between incompatibility and attitudes towards drugs in boy and girl stu- dents. Bahadori et al. (30) also described that there was a negative relationship between resilience and substance abuse among male students and the fact that resilience could predict students' attitudes towards drugs. Rahimi et al. (31) concluded that stress management and resiliency training could effectively decrease perceived stress both in short- and long-term and cause negative attitudes towards drugs among addicted men. Roustaei et al. (32) reported that resilience training was effective on the rate of egocontrol and self-restraint and could improve anger management, impulse control, consideration for others, and responsibility in drug abusers.

\section{Objectives}

Therefore, based on the issues outlined above and regarding the importance of adolescents' and high school students' mental health, the present study aimed to investigate the relationship between social adjustment, resilience, and attitudes towards drugs among boy and girl high school students in Lali city. Figure 1 presents the proposed model of the research design.

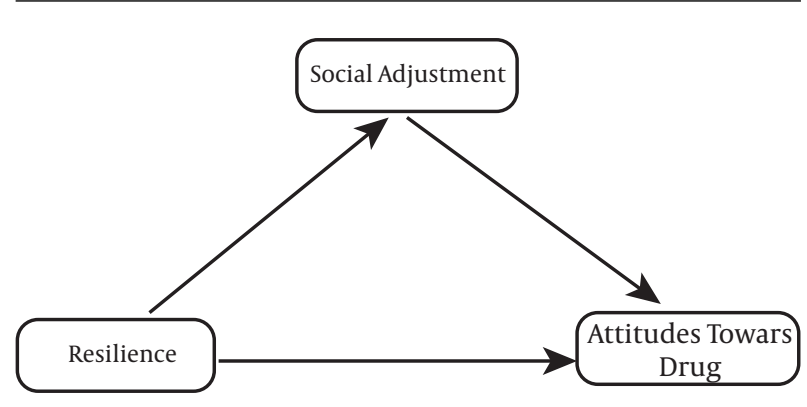

Figure 1. Proposed model of the research

\section{Methods}

This descriptive cross-sectional study was performed by path analysis. The statistical population of the study included 1500 boy and girl high school students in Lali City, Khuzestan Province, Iran, in the academic year of 20172018. The sample population consisted of 133 boy students and 142 girl students, selected through multistage stratified sampling and using Cochran's formula. For this purpose, several high schools were randomly selected in the city of Lali. Then two high schools (one for girls and one for boys) were randomly selected as samples. Questionnaires were distributed among the students. After determining the samples and coordinating with the authorities of Lali City's Education Department, the researcher referred to the schools and provided the participants with 
some explanations about the questionnaires and purposes of the study. Finally, 300 questionnaires were filled and delivered to the researcher. After excluding incomplete questionnaires, a total of 275 questionnaires (133 from boys and 142 from girls) were analyzed. The power of the test indicated the adequacy of the sample size.

\subsection{Research Instruments}

Bell's Adjustment inventory (BAI) for Students: Bell's Adjustment Inventory was designed by Bell in 1961. This scale consists of five components, including home, occupational, health, emotional, and social adjustment. The whole scale includes 32 items answered by the "yes", "no", and "I don't know" choices. The answer of "yes" was assigned a score of 1 , and the answer of "no" was assigned a score of 0 . The total scores of 3 - 6 and 5 - 8 represented a low level of adjustment in boys and girls, respectively. The total scores of 7 - 15 and 9 - 19 indicated a medium level of adjustment in boys and girls, respectively. Finally, the total scores of 16 - 20 and 20 - 24 represented a high level of adjustment in boys and girls, respectively. The obtained total score represented the overall state of adjustment. The reliability of the questionnaire was reported as 0.89 based on Cronbach's alpha coefficient (33). In the present study, Cronbach's alpha coefficient was obtained 0.76 .

\subsubsection{The Connor-Davidson Resilience Scale (CD-RISC) (Persian Version)}

Conner and Davidson (34) designed this scale to measure resilience. This scale consists of 25 items scored based on a five-point Likert scale ranging from zero (quite disagreement) to four (quite agreement) to determine individuals' resilience. The total score is obtained by summing the scores of all the items. The total score ranged from 0 to 100. The higher the total score obtained, the higher is the participant's resilience. The cutoff point of this questionnaire is a score of 50 . In other words, scores above 50 indicate a resilient individual. The higher the score from 50, the higher is the person's resilience. Keyhani et al. (35) reported that the reliability of this questionnaire was equal to 0.78 based on Cronbach's alpha coefficient. In the present study, Cronbach's alpha coefficient of the scale was obtained 0.85 .

\subsubsection{The Drug Attitude Scale (DAS)}

This scale was designed by Rezaee et al. (36) to evaluate students' attitudes towards drugs. This scale consists of 40 items covering three subscales (i.e., the impacts of drug abuse with 21 questions, drug abuse tendency with 10 queries (items 22 - 31), and drug abuse risks with nine questions, items $32-40$ ). This questionnaire is scored based on a five-point Likert scale, including the choices of quite agreement (five scores), agreement (four scores), no idea (three scores), disagreement (two scores), and quite disagreement (one score). The total score of the questionnaire ranged from 40 to 200 . A higher total score reflected a person's more positive attitude towards drugs, and a lower score indicated a more negative attitude and hatred towards drugs (36). In the present study, Cronbach's alpha coefficient of the scale was obtained 0.95 .

\subsection{Statistical Analyses}

Data analysis was done by descriptive and analytical statistics such as mean, standard deviation, minimum, maximum, skewness, kurtosis, and Pearson correlation coefficient. The reliability of the instruments was evaluated by Cronbach's alpha coefficient, and relationships between the variables were studied by path analysis. Meanwhile, the significance of the mediating role was evaluated by the Bootstrap method. The collected data were analyzed using SPSS version 23.

\section{Results}

The mean and standard deviation (SD) for social adjustment, resilience, and attitudes towards drug were 43.64 $\pm 5.82,59.47 \pm 18.90$, and $145.86 \pm 45.92$, respectively, in girl students and $44.46 \pm 5.04,62.67 \pm 17.06$, and 149.87 \pm 45.78 , respectively, in boy students (Table 1 ). Table 1 indicates simple correlations between the research variables, according to which all the research variables had significant correlations with each other. These correlational analyses provided a description of paired relationships between the research variables. Structural equation modeling was used to simultaneously test the relationships assumed in this study.

Before analyzing the data, structural equation modeling was used to evaluate and confirm the assumptions of multivariate normal distribution, linearity, multilinearity, and error independence. The skewness and kurtosis tests were used to assess the data's normal distribution. Given that all the research variables had absolute skewness coefficient values of $<3$ and absolute kurtosis coefficient values of $<10$, the normal distribution of the data was confirmed. Multi-linearity was also checked by tolerance statistics and variance inflation factor (VIF). All the variables had a VIF of $<10$ and a tolerance statistic of $>0.1$, indicating the fulfilment of the non-multi-linearity assumption. Table 2 presents fitness indices for the proposed and final models in boy and girl students. Figure 2 shows the final model, indicating a root mean square error of approximation (RMSEA) of $0.0001, \chi^{2} / \mathrm{df}$ of 0.81 , and CFI of 1.00, suggesting a good fitness model. 


\begin{tabular}{|c|c|c|c|c|c|c|c|c|c|}
\hline \multirow{2}{*}{ Variables } & & \multicolumn{4}{|c|}{ Girl Students } & \multicolumn{4}{|c|}{ Boy Students } \\
\hline & & Mean \pm SD & $\mathbf{1}$ & 2 & 3 & & $\mathbf{1}$ & 2 & 3 \\
\hline \multicolumn{2}{|l|}{ Social adjustment } & $43.64 \pm 5.82$ & 1 & & & $44.46 \pm 5.04$ & 1 & & \\
\hline \multicolumn{2}{|l|}{ Resilience } & $59.47 \pm 18.90$ & $0.24^{\mathrm{a}}$ & 1 & & $62.67 \pm 17.06$ & $0.28^{\mathrm{b}}$ & 1 & \\
\hline \multicolumn{2}{|l|}{ Attitudes towards drugs } & $145.86 \pm 45.92$ & $-0.38^{b}$ & $-0.17^{\mathrm{a}}$ & 1 & $149.87 \pm 45.78$ & $-0.17^{\mathrm{a}}$ & $-0.18^{\mathrm{a}}$ & 1 \\
\hline \multicolumn{10}{|l|}{$\begin{array}{l}{ }^{\mathrm{a}} \mathrm{P}<0.05 \\
{ }^{\mathrm{b}} \mathrm{P}<0.01\end{array}$} \\
\hline \multirow{2}{*}{ Fitness Indicators } & \multicolumn{3}{|c|}{ Girl Students } & \multicolumn{5}{|c|}{ Boy Students } & \\
\hline & Initial Model & \multicolumn{2}{|l|}{ Final Model } & \multicolumn{3}{|c|}{ Initial Model } & \multicolumn{2}{|c|}{ Final Model } & \\
\hline$\chi^{2}$ & 0.000 & 3.65 & & \multicolumn{3}{|c|}{0.000} & \multicolumn{2}{|c|}{4.09} & \\
\hline Df & 0 & 3 & & \multicolumn{3}{|c|}{0} & \multicolumn{2}{|c|}{5} & \\
\hline$\left(\chi^{2} / \mathbf{d f}\right)$ & - & 1.21 & & \multicolumn{3}{|c|}{-} & \multicolumn{2}{|c|}{0.81} & \\
\hline GFI & 1.00 & 0.99 & & \multicolumn{3}{|c|}{1.00} & \multicolumn{2}{|c|}{1.01} & \\
\hline CFI & 1.00 & 0.99 & & \multicolumn{3}{|c|}{1.00} & \multicolumn{2}{|c|}{1.00} & \\
\hline NFI & 1.00 & 0.96 & & \multicolumn{3}{|c|}{1.00} & \multicolumn{2}{|c|}{0.95} & \\
\hline RMSEA & 0.23 & 0.04 & & \multicolumn{3}{|c|}{0.0001} & \multicolumn{2}{|c|}{0.0001} & \\
\hline
\end{tabular}

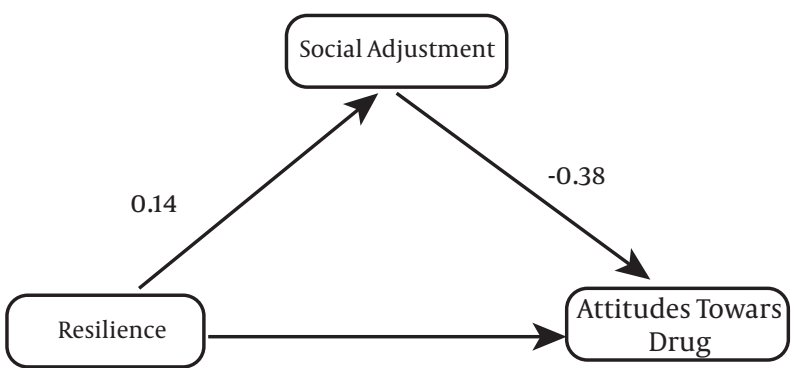

Figure 2. The final modified model

According to Table 3, there was a significant negative relationship between social adjustment and drug attitude in girl students $(\beta=-0.38, \mathrm{P}=0.0001)$; however, there was no significant relationship between social adjustment and drug attitude in boy students $(\beta=-0.07, \mathrm{P}=0.32)$. There was no significant relationship between resilience and drug attitude in boy and girl students; nevertheless, there was a significant positive relationship between resilience and social adjustment in boy and girl students.

Table 4 indicates that the indirect impact of resilience on drug attitude by the mediating role of social adjustment was not statistically significant in boy and girl students.

\section{Discussion}

The present study aimed to investigate the relationship between social adjustment and resilience to drugs in boy and girl students. The results suggested that there was a significant negative relationship between social adjustment and drug attitude in girl students, while the relationship between social adjustment and drug attitude was not significant in boy students. The findings suggested a positive effect for social adjustment on drug attitude, which was consistent with the results reported by Bidi Namdari Pezhman et al. (37), Chen et al. (17), and Murray et al. (15). Social adjustment is a dimension of socialization. Some experts consider social adjustment as an equivalent to social skills. Actually, social adjustment and skills are the capabilities of empowering individuals to predict others' behaviors, control their own behaviors, and regulate their social interactions in an adjusted manner. Moreover, adjustment refers to the ability to associate, adapt, compromise, cooperate, and cope with oneself, the surrounding environment, and other people. An adjusted person is mentally healthy. Rapid and radical changes seriously challenge a person's adjustment ability, causing conflict, stress, and confusion. It can be theoretically stated that people with a high level of social adjustment are less affected by psychological harms such as depression or anxiety and experience less challenges with their parents and peers. These situations pave the ground for tendency towards addictive be- 
Hezarian Set al.

\begin{tabular}{|c|c|c|c|c|c|c|c|}
\hline \multirow{2}{*}{ Path } & \multicolumn{2}{|c|}{ Girl Students } & \multicolumn{5}{|c|}{ Boy Students } \\
\hline & $\beta$ & $\mathbf{P}$ & $\beta$ & \multicolumn{4}{|c|}{$\mathbf{P}$} \\
\hline Social adjustment to drug attitude & -0.38 & $0.000^{\mathrm{b}}$ & -0.07 & \multicolumn{4}{|c|}{0.32} \\
\hline Resilience to drug attitude & -0.09 & 0.20 & -0.04 & \multicolumn{4}{|c|}{0.52} \\
\hline Resilience to social adjustment & 0.14 & $0.05^{\mathrm{a}}$ & 0.24 & \multicolumn{4}{|c|}{$0.003^{\mathrm{b}}$} \\
\hline \multicolumn{8}{|l|}{$\begin{array}{l}{ }^{\mathrm{a}} \mathrm{P}<0.05 \\
{ }^{\mathrm{b}} \mathrm{P}<0.01\end{array}$} \\
\hline \multirow{2}{*}{ Predictor Variable } & \multirow{2}{*}{\multicolumn{2}{|c|}{ Mediator Variable }} & \multirow{2}{*}{ Criterion Variable } & \multicolumn{2}{|c|}{ Girl Students } & \multicolumn{2}{|c|}{ Boy Students } \\
\hline & & & & $\beta$ & $\mathbf{P}$ & $\beta$ & $\mathbf{P}$ \\
\hline Resilience & Social & & Drug attitude & -0.13 & 0.08 & -0.09 & 0.12 \\
\hline
\end{tabular}

haviors or at least create a positive attitude towards addiction. Adolescents' main motive for doing risky behaviors is to get rid of depression and cope with loneliness, anxiety, inabilities, poor self-confidence, and dissatisfaction with life (37). The adolescents experiencing negative emotions about themselves may mingle with their abnormal peers to obtain social acceptance and self-worth. In this context, adolescents may acquire a positive attitude towards drugs when they interact with drug users or those who have relevant experiences.

No significant relationship was found between resilience and drug attitude in boy and girl students. This finding was inconsistent with the results of Sheydae and Pirkhaefi (29), Bahadori et al. (30), and Rahimi et al. (31). Resilience is defined as the skills and capabilities enabling individuals to cope with challenges and difficulties. So, people with a high level of resilience must have a negative attitude towards drugs due to their characteristics. However, our findings suggested the opposite, which may be justifiable by the fact that resilience is not directly related to drug attitude, and this relationship is mediated by other variables. Fadardi et al. (38) reported that motivational structure played a mediating role in the relationship between resilience and drug abuse. The examination of resilience processes at the individual level indicates that young people with good social skills are less likely to be engaged in substance use. The resilience perspective emphasizes that the dynamic processes that give rise to risky and protective mechanisms can offer a more comprehensive approach to both preventive behaviors of a problem, like substance abuse, and the promotion of competent behaviors in the high-risk youth who currently or subsequently may be exposed to risky situations (39).

There was a significant positive relationship between resilience and social adjustment in boy and girl students.
This finding was consistent with the results of Senobar(40) and Hazan Liran and Miller (41). Resilience is defined as the skills and capabilities that enable individuals to cope with challenges and difficulties. Due to their characteristics, people with a high level of resilience experience lower levels of stress and express better coping strategies. So, they are more adjusted and are able to adapt to themselves, their surrounding environment, and others (27). In this study, the indirect effect of resilience on drug attitude by the mediating role of social adjustment was significant in neither boys nor girls. Resilience is the ability to cope with stress, problems, and changes and an opportunity to recognize, strengthen, and enrich protective factors and interactions between oneself and the environment to achieve an intermediate health status in the face of problems. So, due to resistance to stress and adopting proper coping strategies, a resilient person has a high level of mental health and adjustment, and these characteristics are the major indicators of mental health (38). It can be theoretically predicted that resilience affects drug attitude through the mediating role of adjustment because adjustment can improve relationships, decrease challenges, and promote social support. All of these factors are involved in reducing tendency towards drugs.

\subsection{Conclusions}

Resilience affects drug attitude in adolescent students through the mediating role of social adjustment. People with a high level of resilience experience lower levels of stress, so they express better-coping strategies, higher levels of social adjustment, and negative attitudes towards drugs. It is suggested to investigate the role of other variables in predicting drug attitude. 


\section{Footnotes}

Authors' Contribution: Safiollah Hezarian did study concept and design, acquisition of data, analysis, and interpretation of data, and statistical analysis. Saeed Bakhtiarpour and Reza Pasha did administrative, technical, and material support, study supervision. Parviz Asgari and Fariba Hafezi did critical revision of the manuscript for important intellectual content.

Conflict of Interests: No conflict of interest to declare.

Ethical Approval: This article was a part of a PhD dissertation by Safiollah Hezarian in the Department of Psychology, Khuzestan Science and Research Branch, Islamic Azad University, Ahvaz, Iran. The study was approved by the Ethical Committee of Islamic Azad University, Ahvaz Branch.

Funding/Support: This study did not receive any funding.

Informed Consent: Questionnaires were filled after obtaining the participants' satisfaction and written informed consent.

\section{References}

1. Jaworska N, MacQueen G. Adolescence as a unique developmental period. J Psychiatry Neurosci. 2015;40(5):291-3. doi: 10.1503/jpn.150268. [PubMed: 26290063]. [PubMed Central: PMC4543091].

2. Zaky EA. Adolescence: A crucial transitional stage in human life.J Child Adolesc Behav. 2016;4:1-2.

3. Larsen B, Luna B. Adolescence as a neurobiological critical period for the development of higher-order cognition. Neurosci Biobehav Rev. 2018;94:179-95. doi: 10.1016/j.neubiorev.2018.09.005. [PubMed: 30201220]. [PubMed Central: PMC6526538].

4. Kajbaf M, Kooraki M, Saffarian Z. Comparison of psychological disorders in addicted and non adidicted students to the internet in University of Isfahan. Hormozgan Med J. 2014;18(2). e87826.

5. Atzendorf J, Rauschert C, Seitz NN, Lochbuhler K, Kraus L. The Use of Alcohol, Tobacco, Illegal Drugs and Medicines: An Estimate of Consumption and Substance-Related Disorders in Germany. Dtsch Arztebl Int. 2019;116(35-36):577-84. doi: 10.3238/arztebl.2019.0577. [PubMed: 31587705]. [PubMed Central: PMC6804269].

6. Tamanaeifar MR, SedighiArfeei F, Gandomi Z. Relationship between internet addiction with neuroticism in high school students, Kashan, Iran. Hormozgan Med J. 2014;17(1):69-75.

7. Juibari TA, Behrouz B, Attaie M, Farnia V, Golshani S, Moradi M, et al. Characteristics and Correlates of Psychiatric Problems in Wives of Men with Substance-related Disorders, Kermanshah, Iran. Oman Med J. 2018;33(6):512-9. doi: 10.5001/omj.2018.93. [PubMed: 30410694]. [PubMed Central: PMC6206419].

8. Chiu ML, Cheng CF, Liang WM, Lin PT, Wu TN, Chen CY. The Temporal Relationship between Selected Mental Disorders and SubstanceRelated Disorders: A Nationwide Population-Based Cohort Study. Psychiatry J. 2018;2018:5697103. doi: 10.1155/2018/5697103. [PubMed: 30402453]. [PubMed Central: PMC6193334].

9. Hohman ZP, Crano WD, Siegel JT, Alvaro EM. Attitude ambivalence, friend norms, and adolescent drug use. Prev Sci. 2014;15(1):65-74. doi: 10.1007/s11121-013-0368-8. [PubMed: 23404670]. [PubMed Central: PMC3689853].

10. Murphy E, O'Sullivan I, O'Donovan D, Hope A, Davoren MP. The association between parental attitudes and alcohol consumption and adolescent alcohol consumption in Southern Ireland: a cross-sectional study. BMC Public Health. 2016;16(1):821. doi: 10.1186/s12889-016-3504-0. [PubMed: 27538455]. [PubMed Central: PMC4991068].

11. McCuller WJ, Sussman S, Dent CW, Teran L. Concurrent prediction of drug use among high-risk youth. Addict Behav. 2001;26(1):137-42. doi: 10.1016/s0306-4603(00)00082-4. [PubMed: 11196288].

12. Dortaj F, Shakiba M, Shakiba J. The effect of cognitive-behavioral group therapy on social coping of crack abusers. Zahedan J Res Med Sci. 2013;15(2):59-63.

13. Cordier R, Speyer R, Chen YW, Wilkes-Gillan S, Brown T, BourkeTaylor H, et al. Evaluating the Psychometric Quality of Social Skills Measures: A Systematic Review. PLoS One. 2015;10(7). e0132299. doi: 10.1371/journal.pone.0132299. [PubMed: 26151362]. [PubMed Central: PMC4494713].

14. Afshari Azad S, Hejazi S, Allahverdi N. Effective Factors of Drug and Psychotropic Substance Tendencies in Women Referred to Addiction Treatment Centers Affiliated to The Welfare Office in Tehran. Nurs Midwifery J. 2020;17(10):826-39.

15. Murray CB, Lennon JM, Devine KA, Holmbeck GN, Klages K, Potthoff LM. The influence of social adjustment on normative and risky health behaviors in emerging adults with spina bifida. Health Psychol. 2014;33(10):1153-63. doi: 10.1037/hea0000050. [PubMed: 24490647]. [PubMed Central: PMC4442607].

16. Curran T. An actor-partner interdependence analysis of cognitive flexibility and indicators of social adjustment among mother-child dyads. Person Individ Differ. 2018;126:99-103. doi: 10.1016/j.paid.2018.01.025.

17. Chen YL, Chen SH, Gau SS. ADHD and autistic traits, family function, parenting style, and social adjustment for Internet addiction among children and adolescents in Taiwan: a longitudinal study. Res Dev Disabil.2015;39:20-31. doi: 10.1016/j.ridd.2014.12.025. [PubMed: 25617844].

18. Ray CE, Elliott SN. Social Adjustment and Academic Achievement: A Predictive Model for Students With Diverse Academic and Behavior Competencies. Sch Psychol Rev. 2019;35(3):493-501. doi: 10.1080/02796015.2006.12087980.

19. Behzadpoor S, Sohrabi F, Borjali A. The Role of Attentional Control and Resilience in Predicting the Rumination in Patients With ObsessiveCompulsive Disorder. Zahedan J Res Med Sci. 2016;In Press(InPress). doi: 10.17795/zjrms-6249.

20. Malhi GS, Das P, Bell E, Mattingly G, Mannie Z. Modelling resilience in adolescence and adversity: a novel framework to inform research and practice. Transl Psychiatry. 2019;9(1):316. doi: 10.1038/s41398-019-0651-y. [PubMed: 31772187]. [PubMed Central: PMC6879584].

21. Ahmadi S, Toulabi S, Ilanloo H. The Relationship Between Tendency to Substance Abuse and Resilience and Academic Procrastination in Secondary School Students. J Arak Univ Med Sci. 2020:108-17. doi: 10.32598/jams.23.1.5972.1.

22. Kennedy B, Chen R, Fang F, Valdimarsdottir U, Montgomery S, Larsson $\mathrm{H}$, et al. Low stress resilience in late adolescence and risk of smoking, high alcohol consumption and drug use later in life. J Epidemiol Community Health. 2019;73(6):496-501. doi: 10.1136/jech-2018211815. [PubMed: 30718261].

23. Rutter M. Resilience concepts and findings: implications for family therapy.J Fam Ther. 1999;21(2):119-44. doi: 10.1111/1467-6427.00108.

24. Arrington EG, Wilson MN. A Re-Examination of Risk and Resilience During Adolescence: Incorporating Culture and Diversity.J Child Fam Stud. 2000;9(2):221-30. doi:10.1023/a:1009423106045.

25. Kulig JC. Community resiliency: the potential for community health nursing theory development. Public Health Nurs. 2000;17(5):374-85. doi: 10.1046/j.1525-1446.2000.00374.x. [PubMed: 11013000].

26. Clauss-Ehlers CS, Lopez Levi L. Violence and Community, Terms in Conflict: An Ecological Approach to Resilience.J Soc Distress Homeless. 2016;11(4):265-78. doi: 10.1023/a:1016804930977.

27. Ghanbari-Talab M, Fooladchang M. On the relationship of resilience and mental vitality with addiction potential among students. Sci $Q$ Res Addict. 2015;9(34):9-22. 
28. Ganji B, Tavakoli S. Surveying the relationship between psychological capital and academic resiliency with Internet addiction of students. Educ Strat Med Sci. 2018;11(1):102-7.

29. Sheydae R, Pirkhaefi A. The Comparison of Tendency to Addiction and Adjustment in Girls and Boys Students. Sci Q Res Addict. 2010;4(14):5362.

30. Bahadori J, Hashemi T, Bayrami M. The Relationship between Attachment Styles and Resiliency with Attitudes to Drug Use in Students. Res Addict. 2010;4(14):17-30.

31. Rahimi K, Hosseinsabet F, Sohrabi F. Effectiveness of stress management and resiliency training (SMART) on perceived stress and attitude toward drug use among addicted men prisoners. Clin Psychol Stud. 2016;6(22):1-19.

32. Roustaei A, Bakhshipoor B, Doostian Y, Goodiny AA, Koohikar M, Massah O. Effectiveness of Resilience Training on Ego-control and Hardiness of Illicit Drug Users. Addict Health. 2017;9(1):24-31. [PubMed: 29026500]. [PubMed Central: PMC5628765].

33. Alipour Birjandi S, Sahaghi H, Jelodari A. The relationship between perceived social support and Academic self-efficacy with social adjustment. J Develop Strat Med Educ. 2015;2(1):26-37.

34. Connor KM, Davidson JR. Development of a new resilience scale: the Connor-Davidson Resilience Scale (CD-RISC). Depress Anxiety.
2003;18(2):76-82. doi: 10.1002/da.10113. [PubMed: 12964174].

35. Keyhani M, Taghvaei D, Rajabi A, Amirpour B. Internal consistency and confirmatory factor analysis of the Connor-Davidson Resilience Scale (CD-RISC) among nursing female. Iran J Med Educ. 2015;14(10):857-65.

36. Rezaee AM, Delavar A, Najafi M. The construction and validation of opium attitude questionnaire among guidance and high school students. Res Addict. 2013;6(24):37-54.

37. Bidi Namdari Pezhman M, Amani A, Ghanbari S, Kareshki H. Structural analysis of relationship of internet addiction with depression, social adjustment and self-esteem. Avicenna JClin Med.2012;19(3):41-8.

38. Fadardi JS, Azad H, Nemati A. The relationship between resilience, motivational structure, and substance use. Proced Soc Behav Sci. 2010;5:1956-60. doi:10.1016/j.sbspro.2010.07.395.

39. Meschke LL, Patterson JM. Resilience as a Theoretical Basis for Substance Abuse Prevention. J Primary Prevent. 2003;23(4):483-514. doi: 10.1023/a:1022276511537.

40. Senobar A. The relationship between happiness, resilience and academic self-efficacy with academic adjustment of 10th grade male students. Soc Educ. 2018;(8):1-15.

41. Hazan Liran B, Miller P. The Role of Psychological Capital in Academic Adjustment Among University Students. J Happiness Stud. 2017;20(1):51-65. doi: 10.1007/s10902-017-9933-3. 